OPEN ACCESS

Edited by:

Xiaoquan Qi,

Institute of Botany (CAS), China

Reviewed by:

Shan Lu,

Nanjing University, China

Jim Tokuhisa,

Virginia Tech, USA

${ }^{*}$ Correspondence: Marcos Egea-Cortines

marcos.egea@upct.es

Specialty section:

This article was submitted to Plant Metabolism and Chemodiversity,

a section of the journal

Frontiers in Plant Science

Received: 28 July 2016 Accepted: 05 January 2017 Published: 19 January 2017

Citation:

Ruiz-Hernández V, Hermans B, Weiss $J$ and Egea-Cortines M (2017) Genetic Analysis of Natural Variation in Antirrhinum Scent Profiles Identifies BENZOIC ACID CARBOXYMETHYL TRANSFERASE As the Major Locus Controlling Methyl Benzoate Synthesis. Front. Plant Sci. 8:27. doi: 10.3389/fpls.2017.00027

\section{Genetic Analysis of Natural Variation in Antirrhinum Scent Profiles Identifies BENZOIC ACID CARBOXYMETHYL TRANSFERASE As the Major Locus Controlling Methyl Benzoate Synthesis}

\author{
Victoria Ruiz-Hernández, Benjamin Hermans, Julia Weiss and Marcos Egea-Cortines *
}

Genetics, Instituto de Biotecnología Vegetal, Universidad Politécnica de Cartagena, Cartagena, Spain

The Antirrhinum genus has a considerable complexity in the scent profiles produced by different species. We have analyzed the genetic differences between $A$. majus and $A$. linkianum, two species divergent in the emission of methyl benzoate, methyl cinnamate, acetophenone, and ocimene. The genetic analysis showed that all compounds segregated in a Mendelian fashion attributable to one or two loci with simple or epistatic interactions. Several lines lacked methyl benzoate, a major Volatile Organic Compound emitted by $A$. majus but missing in $A$. linkianum. Using a candidate gene approach, we found that the BENZOIC ACID CARBOXYMETHYL TRANSFERASE from A. linkianum appeared to be a null allele as we could not detect mRNA expression. The coding region did not show significant differences that could explain the loss of expression. The intron-exon boundaries was also conserved indicating that there is no alternative splicing in $A$. linkianum as compared to $A$. majus. However, it showed multiple polymorphisms in the $5^{\prime}$ promoter region including two insertions, one harboring an IDLE MITE transposon with additional sequences with high homology to the PLENA locus and a second one with somewhat lower homology to the regulatory region of the VENOSA locus. It also had a 778 bp deletion as compared to the $A$. majus BAMT promoter region. Our results show that the differences in scent emission between $A$. majus and $A$. linkianum may be traced back to single genes involved in discrete biosynthetic reactions such as benzoic acid methylation. Thus, natural variation of this complex trait maybe the result of combinations of wild type, and loss of function alleles in different genes involved in discrete VOCs biosynthesis. Furthermore, the presence of active transposable elements in the genus may account for rapid evolution and instability, raising the possibility of adaptation to local pollinators.

Keywords: recombinant inbred lines, floral scent, transposable element, IDLE MITE, methyl benzoate, acetophenone, $\beta$-ocimene, methyl cinnamate 


\section{INTRODUCTION}

The study of natural variation in natural populations has a great potential for identifying the genetic structure of complex traits. Studies in plants using natural populations have helped to identify a large number of genes involved in different traits such as flowering time, plant architecture, or biomass production (Alonso-Blanco et al., 2009). One of the major traits in plants is the production of secondary metabolites as it can be considered an interface of interaction with living organisms including bacteria, fungi, other plants, and of course animals. The emission of scent by flowers is considered a key trait to attract pollinators and repel potential pests (Schiestl, 2010).

One of the characteristics of floral scent is the complexity in terms of the number of independent Volatile Organic Compounds (VOCs). Some plants such as roses have over 500 VOCs (Spiller et al., 2010), and there are over 1700 compounds identified in floral scent (Knudsen et al., 2006). The genetic studies on scent and volatiles have been an important part of plant biotechnology as the major compounds involved in flavor and aroma are VOCs. As a result, studies in crops such as tomato, peach, rice or strawberry are well-developed (Zorrilla-Fontanesi et al., 2012; Sánchez et al., 2013; Rambla et al., 2014; Golestan Hashemi et al., 2015). The genetics of scent emission and its control has been studied in a variety of plants with different outcomes. Several components of the complex scent profiles of roses have been resolved to single Mendelian loci of one or two genes involved in the synthesis of single VOCs such as nerol, neryl acetate, and geranyl acetate (Spiller et al., 2010). A similar situation has been identified in Mimulus. The differences in pollinator choice in bumblebee-pollinated Mimulus lewisii and hummingbird-pollinated $M$. cardinalis are the result of changes in three volatiles: D-limonene, $\beta$-myrcene, and $\mathrm{E}-\beta$ ocimene (Byers et al., 2014a). The genetic differences lie in two loci coding for a LIMONENE-MYRCENE SYNTHASE and an OCIMENE SYNTHASE (Byers et al., 2014b). A different situation has been described in Petunia. The Petunia genome has a multi locus island involved in the control of scent emission, floral visible color, UV absorption, pistil length, and stamen length (Hermann et al., 2013). Differences between the scented Petunia axillaris and the unscented $P$. exserta lie on two loci. One is a single $M Y B$ gene allelic to ODORANT1 (ODO1) involved in the activation of phenylpropanoids synthesis (Klahre et al., 2011), pointing to a possible evolution at the regulatory level. There is emerging evidence from Petunia and Antirrhinum that scent and floral size may share some corregulators such as ENHANCER OF BENZENOID II in Petunia, involved in scent emission, flower opening, and anthesis (Colquhoun et al., 2011; Van Moerkercke et al., 2011). In Antirrhinum the gene COMPACTA is involved in maintenance of $\mathrm{B}$ function affecting petal size and scent emission (Manchado-Rojo et al., 2012). A study of narrow sense heritability in Brassica rapa has shown that although scent profiles between species differ in many cases in a number of independent VOCs, they may have coregulation between them and with other morphological traits or flowering time ( $\mathrm{Zu}$ et al., 2016). The genes involved in single compound biosynthesis together with regulatory loci with several genetic functions indicates that the natural variation of scent emission may identify both regulatory loci as in Petunia and structural genes involved in discrete VOCs biosynthesis, or form part of larger pathways, affecting downstream products.

The systematic identification of enzymes responsible for the biosynthesis of many volatiles and secondary metabolites has followed a standard protocol. Coding regions have been expressed in a heterologous system such as bacteria, yeast or plant cells, and the enzyme activity has allowed the identification of the corresponding basic biochemical properties such as $\mathrm{Km}$ for different substrates. Such studies have determined enzyme activities involved in biosynthesis of alkaloids, phenylpropanoids, benzenoids etc. (Murfitt et al., 2000; Collu et al., 2001; Dudareva et al., 2003). However, the identification of genetic variation and the corresponding allelic differences allowing unequivocal annotation of the different coding genes in plants is lagging behind. This is especially important as some enzymes have been found to be able to produce more than one product in vitro and may act on different substrates in vivo.

The genus Antirrhinum comprises roughly 28 species with a center of origin in the Iberian Peninsula (Vargas et al., 2009). Work in Antirrhinum has shown that methyl benzoate, myrcene, and nerolidol are produced in a circadian fashion (Kolosova et al., 2001a; Dudareva et al., 2005). The complexity of scent components is reflected in the identification of at least 120 VOCs previously described in plants (Weiss et al., 2016b). In this work, we have performed a genetic analysis of scent emission spanning three generations following a cross of A. majus and A. linkianum. Both species differ in the production of four VOCS: methyl benzoate, $\beta$-ocimene, methyl cinnamate, and acetophenone. These compounds displayed Mendelian segregations typical for a single gene or two loci in the F2 population. We identified a loss of function allele of BENZOIC ACID CARBOXYMETHYL TRANSFERASE (BAMT), a gene involved in methyl benzoate synthesis in higher plants. The null allele is the result of a genomic insertion in the promoter region that was likely mediated by an IDLE MITE transposable element (Cartolano et al., 2007) in conjunction with additional genomic rearrangements including a second insertion of genomic sequences with similarity to the VENOSA locus (Schwinn et al., 2006). The underlying activity of transposable elements may represent a mechanism for the rapid evolution of scent profiles by promoting genomic rearrangements in key VOC biosynthetic enzymes or their regulatory elements.

\section{MATERIALS AND METHODS}

\section{Plant Material and Growth Conditions}

Plants of Antirrhinum majus and A. linkianum were grown as described previously as a single plant per pot allowing maximum number of flowers to be produced (Weiss et al., 2016a). We performed a cross between A. majus line 165E and A. linkianum to obtain a recombinant inbred line.

\section{VOC Collection}

Plants belonging to the F2 or F3 segregating population were sampled once and in those cases where little or no scent was 
obtained a second resampling was performed. Flowers were incubated in a $25 \mathrm{ml}$ glass beaker containing $4 \mathrm{ml}$ of $5 \%$ glucose. The pedicel was in contact with the solution. The glass beakers were placed inside 11 glass desiccators under a regime of 12:12 light dark and $23-18^{\circ} \mathrm{C}$ conditions. Samples were taken for 24 $\mathrm{h}$ periods. Flowers were weighted before and after the scent collection. Quantification of scent emission was based on flower total emission.

\section{Gas-Chromatography Mass Spectrometry}

Trapped floral volatiles were analyzed by gas chromatographymass spectrometry (GC-MS) as described (Manchado-Rojo et al., 2012). Data analysis and volatile identification was performed with the MSD ChemStation (Agilent Technologies) software.

For semi-quantifying the main VOC compounds of the RILs (methyl benzoate, methyl cinnamate, acetophenone, and $\beta$ ocimene) we used standard solutions (Sigma-Aldrich products codes: 18344, 96410, 42163, W353901) diluted with methanol. The concentration of $\beta$-ocimene ranged from 25 to $1250 \mathrm{ppm}$, whereas the concentration of the rest of compounds ranged from 50 to $2500 \mathrm{ppm}$. An injection volume of $0.5 \mu \mathrm{l}$ was applied directly to a Twister ${ }^{\mathrm{TM}}$. The standards were directly injected using a split/splitless injector (Agilent Technologies). Calibration curves were calculated by Chemstation (methyl benzoate: $1.181^{*} 10^{7} \mathrm{x}-1.009^{*} 10^{5}, r^{2}=0.999$; methyl cinnamate: $1.762^{*} 10^{7} \mathrm{x}-5.245^{*} 10^{5}, r^{2}=1$; acetophenone: $1.052^{*} 10^{7} \mathrm{x}-$ $2.693^{*} 10^{5}, r^{2}=0.999 ; \beta$-ocimene $(\mathrm{Z}): 8.318^{*} 10^{6} \mathrm{x}-1.397^{*} 10^{5}$, $\left.r^{2}=0.999\right)$. The corresponding calibration curves were used to quantify the major compounds segregating. Total amounts are given in $\mu \mathrm{g} \cdot$ flower $^{-1} \cdot 24 \mathrm{~h}^{-1}$ and in $\mu \mathrm{g} \cdot$ fresh weight (fw) $)^{-1} \cdot 24 \mathrm{~h}^{-1}$.

\section{Cloning of $A$. linkianum BAMT}

We obtained sequence information of Antirrhinum majus and developed PCR primers to amplify the genomic region corresponding to BAMT (AF198492.1). We amplified the complete coding region and $2.1 \mathrm{~kb}$ corresponding to the $5^{\prime}$ region upstream of the coding region from A. majus $165 E$ and A. linkianum (Table S1) using TAKARA PrimeStar GXL TAQ polymerase. The amplified DNA fragments were T/A cloned in pGEMTEasy according to the manual and grown in DH10B E. coli. DNA sequence was determined by Sanger using standard primers for pGEMTeasy. The accession numbers of the sequences are KU512977 A. majus BAMT and KU512978 for A. linkianum BAMT.

\section{qPCR}

We analyzed the steady state accumulation of transcripts coding for $B A M T$ by qPCR as described before (Delgado-Benarroch et al., 2009). Petals were sampled at T6 subjective time being T0 dawn, as it coincides with the highest AmajusBAMT expression (Kolosova et al., 2001a). Total RNA was extracted from fully developed petals using the RNAEasy Kit from Macherey and Nagel according to the instructions. Genes were amplified in a Stratagene Mx3000 qPCR machine (www.agilent.com), with sequence-specific primers (Table S1) synthesized by Invitrogen (www.invitrogen.com) using Takara SYBR-Green (www.thermofischer.com). We used the gene UBIQUITIN CONJUGATING ENZYME2 (accession number AJ560266.1; Bey et al., 2004) as a control for normalization. The PCR program was performed with 45 cycles including a 10 min denaturation at $95^{\circ}$ followed by $30 \mathrm{~s}$ at $56^{\circ}, 45 \mathrm{~s}$ at $72^{\circ}$, and $30 \mathrm{~s}$ at $95^{\circ}$. We performed experiments with one biological replica and two technical replicas for each of the lines analyzed. The experiment was repeated twice including mRNA extractions with similar results.

\section{RESULTS}

\section{Construction of Recombinant Inbred Lines}

We had previously found that Antirhinum majus 165E and A. linkianum differ in the emission of four main floral scent VOCs, methyl benzoate, methyl cinnamate, $\beta$-ocimene, and acetophenone (Weiss et al., 2016b). In order to identify the genetic components involved in the differential emission, we constructed an F2 from A. majus line $165 \mathrm{E} \times$ A. linkianum (Figure 1). The $A$. majus line $165 \mathrm{E}$ has a strong activity

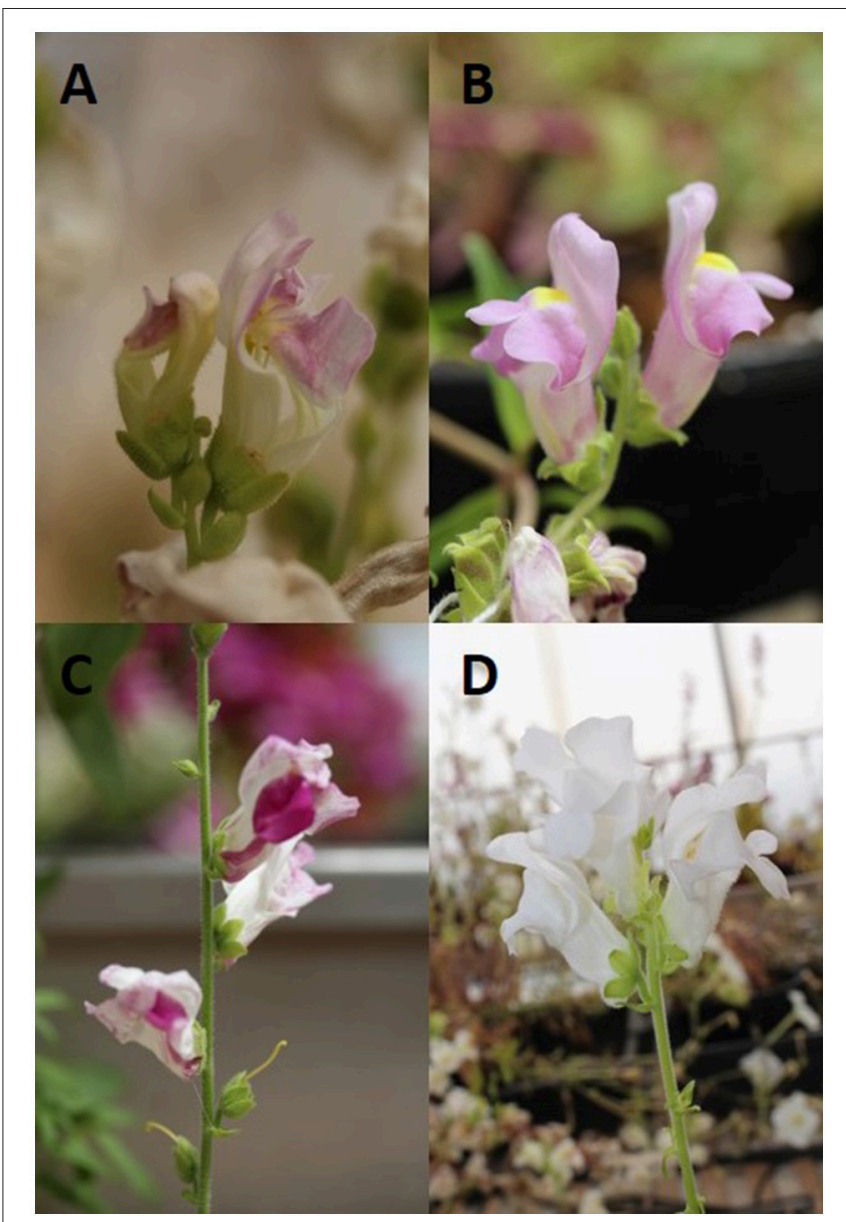

FIGURE 1 | Pictures of flowers of (A) Antirrhinum majus 165E (B) A. linkianum and two F2 siblings differing in color. (C) The transposon activity could be noted and (D) showing white flowers. 
of transposable elements and is mutated in the PALLIDA locus coding dihydroflavonol-4-reductase (Martin et al., 1985). This enzyme catalyzes the reduction of dihydroquercetin to leucocyanidin, during the last steps in anthocyanin biosynthesis thus allowing the visual monitoring of transposon activity in the flowers.

We obtained an initial population of $174 \mathrm{~F} 2$ plants. We used a total of $110 \mathrm{~F} 2$ plants that flowered during a period of 5 months to analyze scent production and selfed the plants to obtain further inbred lines.

\section{Genetic Analysis of Scent Profiles}

We identified a number of individuals in the F2 that produced either low or close to undetectable levels of the four VOCs that are contrasting between the parental lines (Table 1). We analyzed the segregation of the compounds and found a range of methyl benzoate emission between $203.41 \mu \mathrm{g}$. flower $^{-1} \cdot 24$ $\mathrm{h}^{-1}$ from line 39 and down to $1.12 \mu \mathrm{g}$.flower ${ }^{-1} \cdot 24 \mathrm{~h}^{-1}$ from line 1 (Figure 2). The emission of $\beta$-ocimene ranged between $372.91 \mu \mathrm{g} \cdot$ flower $^{-1} \cdot 24 \mathrm{~h}^{-1}$ from line 4 and 1.85 $\mu \mathrm{g} \cdot$ flower $^{-1} \cdot 24 \mathrm{~h}^{-1}$ from line 96 . The emission of methyl cinnamate ranged between $48.07 \mu \mathrm{g} \cdot$ flower $^{-1} \cdot 24 \mathrm{~h}^{-1}$ from line 102 and was $0.03 \mu \mathrm{g} \cdot$ flower $^{-1} \cdot 24 \mathrm{~h}^{-1}$ from lines $16,29,31,36$, $43,62,86,108$, and 112 . Finally, acetophenone emission ranged between $304.29 \mu \mathrm{g} \cdot$ flower $^{-1} \cdot 24 \mathrm{~h}^{-1}$ from line 19 and down to $0.03 \mu \mathrm{g} \cdot$ flower $^{-1} \cdot 24 \mathrm{~h}^{-1}$ from line 47 .

We analyzed the data of the different scent components to identify a possible genetic model of segregation for each of the VOCS, considering the current knowledge at the biochemical level (Figure 3). The enzyme benzoic acid carboxymethyltransferase (BAMT) is the major enzyme involved in the synthesis of methyl benzoate (Dudareva et al., 2000; Murfitt et al., 2000; Effmert et al., 2005). The segregation analysis of plants producing high and low amounts of methyl benzoate complied to a model of a single gene with Mendelian 3:1 segregation (Chi square test $p=0.582$ ), where the plants producing methyl benzoate were dominant (Table 2). This indicated that the allele of $A$. linkianum BAMT could be a major candidate gene involved in the synthesis of methyl benzoate. Furthermore $A$. linkianum BAMT should probably code for a loss of function allele.

The synthesis of $\beta$-ocimene in $A$. majus is performed by a specific $\beta$-ocimene synthase (Dudareva et al., 2003). The emission of $\beta$-ocimene followed a similar pattern as methyl benzoate but in contrast, the number of plants producing low or very low amounts was lower. In fact, we always found small amounts of $\beta$-ocimene indicating that a possible allele of $A$. majus OCS was a hypomorphic allele but not a complete null. We tested the hypothesis of a single gene segregating taking into account three different thresholds of emission. The most strict showed significant differences to a 3:1 Mendelian segregation ( $p=0.002953$; Table 2). A slightly less conservative cutoff at levels below $30 \mu \mathrm{g}$.flower ${ }^{-1} \cdot 24 \mathrm{~h}^{-1}$ did result in acceptable statistical fits $(p=0.9 .123)$. Using the strict threshold below $10 \mu \mathrm{g}$.flower ${ }^{-1} \cdot 24 \mathrm{~h}^{-1}$, we also found a possible model for a $13: 3$ segregation ( $p=0.1056)$ where two genes would come into play (Table 2).
TABLE 1 | A. majus $\times$ A. linkianum (F2) emission of methyl benzoate, $\beta$-ocimene, methyl cinnamate, and acetophenone $\left(\mu \mathrm{g} \cdot \mathrm{FLOWER}^{-1} \cdot 24 \mathrm{~h}^{-1}\right)$.

\begin{tabular}{|c|c|c|c|c|}
\hline Line & $\begin{array}{c}\text { Methyl } \\
\text { benzoate }\end{array}$ & $\beta$-ocimene & $\begin{array}{l}\text { Methyl } \\
\text { cinnamate }\end{array}$ & Acetophenone \\
\hline 1 & 1.12 & 37.35 & 0.20 & 0.74 \\
\hline 2 & 42.91 & 103.67 & 4.26 & 10.06 \\
\hline 3 & 3.69 & 175.77 & 0.56 & 186.78 \\
\hline 4 & 53.32 & 372.91 & 15.48 & 260.36 \\
\hline 5 & 37.56 & 92.09 & 0.30 & 32.01 \\
\hline 6 & 15.72 & 11.64 & 0.39 & 2.61 \\
\hline 7 & 13.17 & 97.24 & 0.46 & 91.23 \\
\hline 8 & 6.98 & 79.04 & 15.20 & 2.98 \\
\hline 9 & 1.22 & 94.81 & 3.52 & 0.26 \\
\hline 10 & 126.67 & 100.64 & 1.08 & 11.95 \\
\hline 11 & 123.12 & 35.91 & 0.43 & 75.31 \\
\hline 12 & 30.62 & 32.59 & 0.86 & 9.43 \\
\hline 13 & 40.25 & 31.57 & 23.67 & 303.03 \\
\hline 15 & 80.92 & 57.42 & 7.04 & 66.73 \\
\hline 16 & 1.39 & 7.99 & 0.03 & 0.49 \\
\hline 18 & 54.50 & 51.17 & 0.29 & 27.95 \\
\hline 19 & 17.13 & 186.93 & 2.19 & 304.29 \\
\hline 21 & 5.25 & 97.26 & 0.52 & 0.15 \\
\hline 22 & 44.19 & 113.57 & 0.08 & 11.94 \\
\hline 23 & 47.14 & 96.41 & 0.10 & 88.92 \\
\hline 24 & 37.50 & 29.06 & 0.74 & 29.53 \\
\hline 25 & 11.08 & 5.62 & 0.75 & 40.70 \\
\hline 27 & 0.56 & 82.47 & 3.10 & 0.21 \\
\hline 29 & 14.30 & 53.98 & 0.03 & 48.07 \\
\hline 31 & 43.09 & 29.12 & 0.03 & 14.26 \\
\hline 32 & 1.05 & 65.38 & 1.25 & 0.77 \\
\hline 33 & 11.92 & 71.76 & 0.12 & 35.70 \\
\hline 34 & 1.14 & 11.89 & 5.25 & 0.88 \\
\hline 35 & 38.17 & 3.28 & 1.09 & 74.16 \\
\hline 36 & 2.01 & 1.95 & 0.03 & 2.38 \\
\hline 37 & 94.29 & 210.09 & 13.99 & 3.70 \\
\hline 38 & 2.24 & 76.58 & 0.09 & 1.51 \\
\hline 39 & 203.41 & 325.85 & 4.04 & 12.29 \\
\hline 40 & 42.63 & 36.71 & 1.50 & 88.72 \\
\hline 41 & 15.59 & 32.86 & 2.25 & 19.46 \\
\hline 42 & 67.66 & 32.76 & 1.11 & 24.65 \\
\hline 43 & 66.69 & 143.26 & 0.03 & 0.56 \\
\hline 44 & 37.82 & 72.15 & 0.15 & 160.01 \\
\hline 47 & 146.77 & 284.77 & 35.47 & 0.03 \\
\hline 48 & 74.83 & 67.91 & 45.13 & 25.83 \\
\hline 51 & 162.06 & 236.10 & 2.42 & 246.65 \\
\hline 52 & 11.64 & 3.89 & 0.08 & 7.11 \\
\hline 53 & 58.37 & 20.86 & 0.09 & 53.34 \\
\hline 56 & 3.75 & 5.25 & 22.78 & 1.65 \\
\hline 57 & 43.21 & 69.50 & 1.77 & 19.54 \\
\hline 58 & 60.24 & 7.48 & 1.76 & 79.76 \\
\hline 60 & 26.40 & 4.73 & 0.19 & 20.00 \\
\hline 62 & 3.71 & 28.65 & 0.03 & 25.30 \\
\hline 64 & 2.52 & 75.33 & 2.50 & 0.85 \\
\hline
\end{tabular}

(Continued) 
TABLE 1 | Continued

\begin{tabular}{|c|c|c|c|c|}
\hline Line & $\begin{array}{c}\text { Methyl } \\
\text { benzoate }\end{array}$ & $\beta$-ocimene & $\begin{array}{c}\text { Methyl } \\
\text { cinnamate }\end{array}$ & Acetophenone \\
\hline 65 & 4.55 & 78.02 & 0.23 & 14.31 \\
\hline 66 & 74.04 & 105.48 & 2.38 & 125.28 \\
\hline 67 & 2.87 & 97.26 & 0.27 & 4.94 \\
\hline 68 & 54.99 & 138.41 & 38.11 & 69.35 \\
\hline 69 & 21.47 & 14.26 & 30.28 & 2.87 \\
\hline 71 & 12.28 & 73.29 & 0.99 & 19.83 \\
\hline 72 & 16.3 & 13.58 & 4.75 & 96.63 \\
\hline 73 & 1.22 & 21.24 & 19.07 & 2.27 \\
\hline 74 & 5.17 & 240.55 & 14.42 & 1.1 \\
\hline 75 & 67.83 & 298.36 & 11.63 & 122.75 \\
\hline 76 & 87.3 & 126.57 & 1.55 & 19.56 \\
\hline 78 & 1.13 & 91.79 & 0.81 & 93.54 \\
\hline 79 & 86.43 & 81.75 & 2.05 & 64.87 \\
\hline 80 & 46.83 & 2.55 & 3.77 & 55.66 \\
\hline 83 & 41.98 & 199.34 & 5.08 & 3.2 \\
\hline 85 & 43.1 & 130.71 & 0.1 & 133.19 \\
\hline 86 & 52.21 & 103.41 & 0.03 & 42.49 \\
\hline 87 & 77.98 & 199.87 & 1.75 & 289.0 \\
\hline 88 & 97.71 & 220.32 & 9.82 & 7.0 \\
\hline 89 & 53.87 & 74.45 & 2.43 & 9.15 \\
\hline 90 & 16.0 & 84.57 & 0.37 & 21.21 \\
\hline 91 & 39.11 & 62.58 & 0.84 & 15.83 \\
\hline 93 & 33.63 & 199.62 & 5.55 & 3.92 \\
\hline 95 & 26.36 & 23.56 & 0.14 & 11.41 \\
\hline 96 & 12.46 & 1.85 & 16.44 & 2.67 \\
\hline 97 & 68.79 & 52.54 & 16.42 & 172.94 \\
\hline 98 & 5.8 & 51.46 & 20.51 & 3.69 \\
\hline 99 & 139.65 & 51.17 & 21.95 & 166.28 \\
\hline 100 & 60.08 & 22.76 & 6.12 & 17.67 \\
\hline 101 & 19.24 & 28.21 & 0.8 & 1.4 \\
\hline 102 & 64.38 & 31.43 & 48.07 & 6.94 \\
\hline 103 & 89.71 & 146.16 & 0.2 & 7.2 \\
\hline 104 & 13.37 & 3.32 & 0.33 & 1.1 \\
\hline 105 & 19.74 & 63.48 & 25.82 & 3.51 \\
\hline 106 & 28.71 & 90.44 & 12.03 & 1.74 \\
\hline 107 & 1.76 & 54.66 & 6.81 & 3.63 \\
\hline 108 & 42.9 & 79.91 & 0.03 & 266.72 \\
\hline 109 & 168.38 & 148.08 & 0.1 & 373.39 \\
\hline 110 & 64.48 & 128.9 & 3.33 & 18.46 \\
\hline 111 & 95.91 & 22.79 & 0.6 & 35.11 \\
\hline 112 & 88.53 & 118.99 & 0.03 & 75.56 \\
\hline 113 & 61.93 & 41.29 & 3.41 & 108.44 \\
\hline 114 & 2.88 & 166.18 & 0.12 & 1.52 \\
\hline 115 & 66.17 & 85.87 & 0.08 & 71.67 \\
\hline 116 & 1.92 & 2.97 & 0.37 & 2.29 \\
\hline 117 & 195.26 & 82.87 & 0.2 & 211.54 \\
\hline 118 & 36.98 & 4.44 & 0.66 & 33.23 \\
\hline 119 & 25.78 & 30.85 & 0.76 & 44.79 \\
\hline 120 & 84.16 & 99.84 & 0.13 & 61.18 \\
\hline 121 & 29.72 & 104.68 & 10.87 & 126.79 \\
\hline
\end{tabular}

(Continued)
TABLE 1 | Continued

\begin{tabular}{lrrcc}
\hline Line & $\begin{array}{c}\text { Methyl } \\
\text { benzoate }\end{array}$ & $\beta$-ocimene & $\begin{array}{c}\text { Methyl } \\
\text { cinnamate }\end{array}$ & Acetophenone \\
\hline 122 & 69.82 & 87.67 & 10.87 & 123.69 \\
123 & 21.13 & 78.98 & 17.6 & 0.49 \\
124 & 60.34 & 154.03 & 0.08 & 184.3 \\
125 & 64.47 & 193.11 & 9.51 & 154.08 \\
126 & 56.69 & 188.98 & 15.91 & 198.31 \\
127 & 28.44 & 56.75 & 0.1 & 1.55 \\
129 & 2.85 & 252.88 & 4.71 & 249.51 \\
130 & 49.88 & 114.28 & 1.68 & 29.64 \\
131 & 50.46 & 50.27 & 0.08 & 4.38 \\
132 & 9.62 & 6.39 & 0.06 & 6.3 \\
133 & 155.67 & 197.02 & 3.89 & 114.4 \\
\hline
\end{tabular}

The synthesis of methyl cinnamate is produced by the cinnamate/p-coumarate carboxylmethyltransferases (CCMTs; Kapteyn et al., 2007), in what appears to be a single gene scheme in Ocium basilicum. The data inspection showed a clear cut group of 87 plants that produced little or no methyl cinnamate (Figure 2) and a set of 23 that produced substantially higher levels. This data distribution fit perfectly to a 3:1 Mendelian model ( $p=0.3218$; Table 2) albeit with a dominant allele that did not produce methyl cinnamate and a recessive allele that produced this volatile. Thus, there is either a suppressor in trans or a dominant negative allele of the corresponding gene in the $A$. majus genetic background.

Finally, the synthesis of acetophenone is thought to be a degradation of ethylbenzene in bacteria. The degradation of 1-phenylethanol is caused by two enzymes a naphthalene dioxygenase and 1-phenylethanol dehydrogenase (Simon et al., 1993; Kniemeyer and Heider, 2001). We found what appeared to be a relative large number of lines producing very little acetophenone (41) indicating a possible effect of two genes. Indeed single gene models were significantly different from a 3:1 $(p=0.002354)$ or $1: 2: 1 \quad(p=0.0001789$; Table 2$)$. However, a 9:7 epistatic segregation was statistically possible $(p=0.1966)$ indicating the probable effect of two genes in the synthesis of acetophenone as proposed in bacteria. As found for $\beta$-ocimene, the A. linkianum alleles involved in acetophenone synthesis or its control, may not be null alleles resulting in small albeit detectable emissions.

\section{Coding Region of $A$. linkianum BAMT}

We decided to analyze the molecular structure of the $A$. linkianumBAMT allele segregating in the population. In order to identify possible lesions responsible for the loss of methyl benzoate emission we followed a candidate gene approach. Previous work has shown that the coding region of benzoic acid carboxymethyl transferase purified from petal tissue of Antirrhinum and expressed in E. coli can produce methyl benzoate, giving unequivocal biochemical support for the function of the corresponding gene product (Murfitt et al., 2000). Further, analysis of the protein expression has shown 


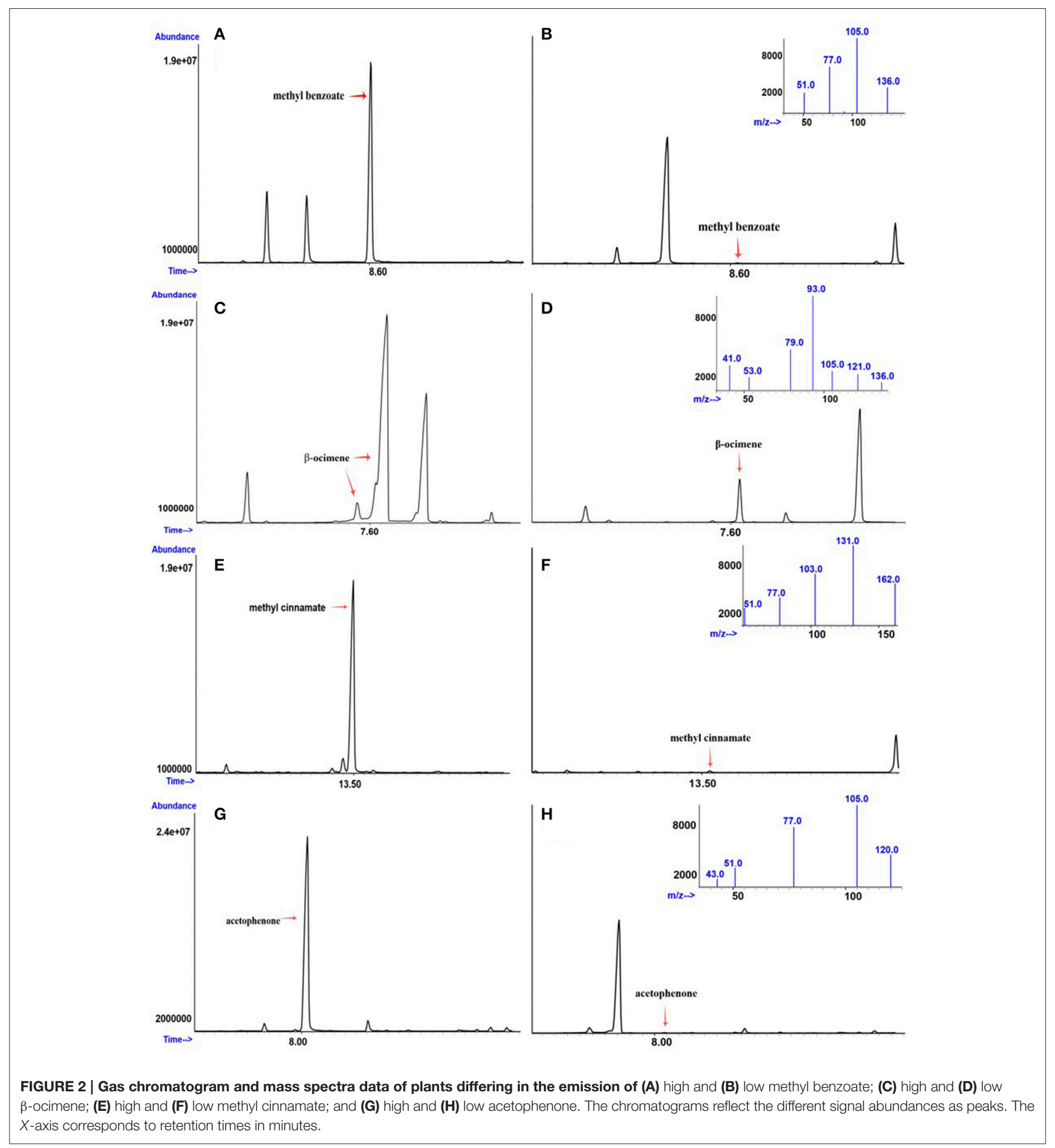

that A. majusBAMT is expressed in petals (Kolosova et al., 2001b), the tissue that produces methyl benzoate. Despite the biochemical and cellular evidence, there was no genetic evidence that A. majus BAMT is the major gene involved in the synthesis of methyl benzoate. This is especially critical as there are two additional enzymes, salicylic acid carboxymethyl transferase (SAMT) and jasmonic acid carboxymethyl transferase (JAMT) with similar structure. Even though SAMT has a low $\mathrm{Km}$ for benzoic acid it is able to produce methyl benzoate in vitro (Negre et al., 2002; Effmert et al., 2005) and it may be able to produce some methyl benzoate in vivo. 


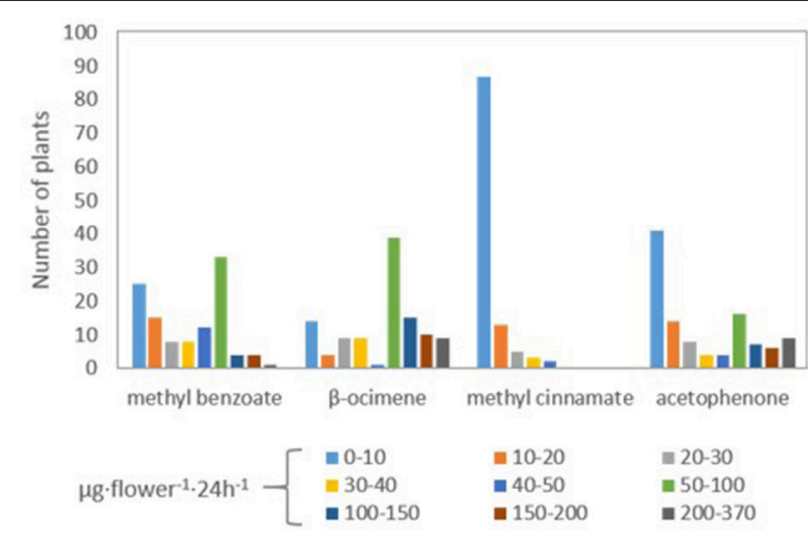

FIGURE 3 | Quantification of the number of plants emitting different quantities of methyl benzoate, $\beta$-ocimene, methyl cinnamate, and acetophenone.

TABLE 2 | Statistical analysis of the Mendelian segregation in an F2 population of methyl benzoate, $\beta$-ocimene, methyl cinnamate, and acetophenone in a cross of $A$. majus $\times$ A. linkianum ( $n=110$ plants).

\begin{tabular}{lcc}
\hline Compound & Segregation model & Chi square $\boldsymbol{P}$-value \\
\hline Methyl benzoate & $3: 1(85: 25)$ & 0.582 \\
\hline$\beta$-ocimene & $3: 1(96: 14)$ & 0.002953 \\
$3: 1(92: 18)$ & 0.03645 \\
$3: 1(83: 27)$ & 0.9123 \\
$13: 3(96: 14)$ & 0.1056 \\
\hline Methyl cinnamate & $3: 1(87: 23)$ & 0.3218 \\
\hline Acetophenone & $3: 1(68: 41)$ & 0.002354 \\
& $1: 2: 1(41: 46: 22)$ & 0.0001789 \\
$9: 7(68: 41)$ & 0.1966 \\
\hline
\end{tabular}

We used the published sequence of $A$. majus BAMT to design primers to amplify the coding region of $A$. linkianum BAMT from gDNA in plants that were not producing methyl benzoate (Table S1). We used petal tissues from F3 plants producing large amounts of methyl benzoate and very low to undetectable levels (Figure 4). We could not detect A. linkianum BAMT expression in plants that did not emit methyl benzoate (Figure 4). The PCR primers developed to amplify a fragment of A. linkianum and A. majus turned out to be in a conserved region of the cDNA corresponding to the fourth exon, suggesting that the lack of amplification was not due to lack of annealing of the designed primers (Supplementary Figure 1).

The BAMT coding sequence in A. majus is composed of four exons $(1110 \mathrm{bp})$. As the expression of BAMT in plants that do not produce methyl benzoate was undetectable, we used the genomic DNA of the parental A. linkianum to sequence the $A$. linkianum BAMT allele. We found a total of 40 SNPs in the coding region as compared to $A$. majus. These polymorphisms at the DNA level caused 15 amino acid changes at the protein level (Figure 5; Supplementary Figure 1). The mutations identified fell into two groups, one of conserved amino acid changes inside the BAMT/SAMT family of proteins and a second one of nonconserved amino acids. There were 10 amino acid changes in the first group but all the mutations corresponded to conservative amino acid substitutions. The amino acid His36 of A. majus BAMT is a proline in the proteins analyzed (Figure 5, Table 3) but was substituted by Arg in A. linkianum BAMT, that is conserved in the Arabidopsis thaliana JAMT (AT1G19640). The Ala69 from A. majus BAMT was conserved with Clarkia breweri SAMT but was substituted by a Thr in A. linkianum BAMT, that is conserved in most of the species analyzed. The second group of mutations comprised five amino acid changes in positions that are not conserved in the SHABAT proteins. The amino acid differences did not explain the complete lack of mRNA expression, indicating a different source of change.

We examined the exon-intron boundaries of the AmajusBAMT and AlinkianumBAMT genes. Both were identical at the exon-intron boundaries, except for a single base pair (596) within the third intron and four base pairs $3^{\prime}$ of the exon-intron boundary predicted by the AmajusBAMT annealing of genomic and cDNA sequences (Supplementary Figure 1). Using the $A$. linkianum sequence to predict possible exon-intron boundaries (Huang et al., 2006) for the corresponding interval where the 596 SNP occurs (bp400-700), gave as a result a splicing site identical to the exon-intron structure of AmajusBAMT. Thus, an alternative splicing that would produce a cDNA fragment lacking the last two exons, is not probable.

\section{Genomic Structure of $A$. linkianum BAMT}

We developed additional PCR primers based on the promoter region of $A$. majus BAMT and amplified $2125 \mathrm{bp}$ of the promoter region of $A$. majus, and the corresponding region from the A. linkianum genome. The A. linkianum promoter was longer (2592 bp; Figure 6A) suggesting major changes in the promoter structure.

We divided the A. linkianumBAMT promoter in six fragments from $5^{\prime}$ to $3^{\prime}$ corresponding to six regions with distinct features (Figure 6B). We numbered the promoter with 1 as the adenine in the ATG of the BAMT CDS. The most distal fragment, -2592 to -2394 bp showed high homology to the A. majus promoter $(-2125$ to $-1927 \mathrm{bp})$ and contained 10 SNPs (Supplementary Figure 2). The second fragment of A. linkianum BAMT (-2393 to $-1763 \mathrm{bp}$ ) had a $631 \mathrm{bp}$ insertion comparing to the A. majus promoter, located between the $-1926 \mathrm{bp}$ and the $-1925 \mathrm{bp}$ of A. majus. This insertion included genomic DNA that showed an extreme degree of homology (BLASTN e-114) with a fragment found in the promoter region of the PLENA locus (Figure 7; Bradley et al., 1993). This insertion contained an IDLE MITE transposable element (Figure 6; Cartolano et al., 2007; SchwarzSommer et al., 2010). The following fragment ( -1762 to -1624 bp) of 138 bp length showed again high homology to the A. majus promoter $(-1925$ to $-1786 \mathrm{bp})$ and had 6 SNPs. There was a 778 bp deletion in the $A$. linkianum promoter comprising the region between -1785 and -1006 bp from the A. majus promoter. The following fragment from -1623 to $-1463 \mathrm{bp}$ comprised $160 \mathrm{bp}$ homologous to A. majus ( -1007 to $-852 \mathrm{bp}$ ) with 6 SNPs and a 4 bp insertion. The following fragment was an insertion of 608 

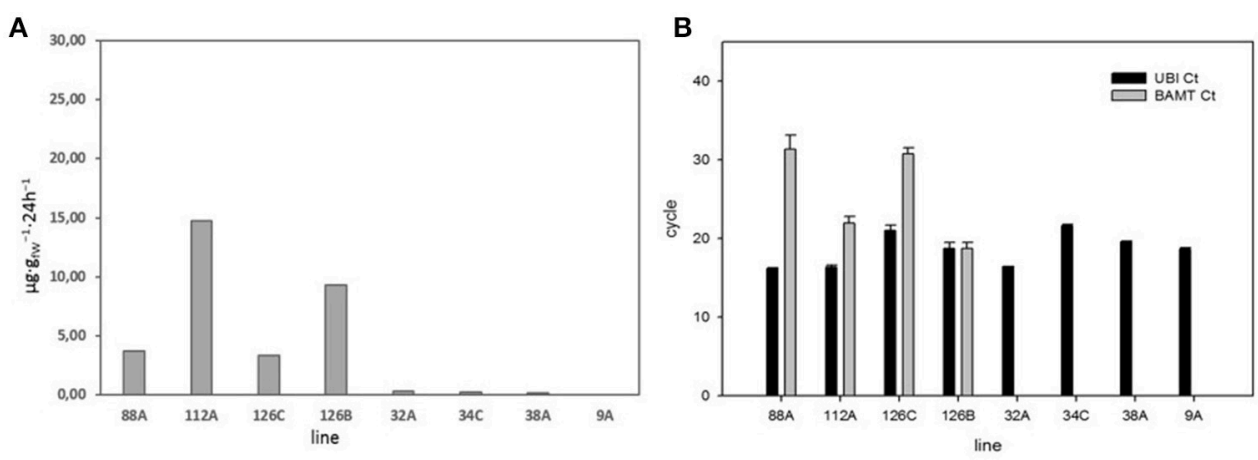

FIGURE 4 | (A) Emission of methyl benzoate in eight F3 lines with high and low emissions of methyl benzoate. (B) Quantitative PCR of BAMT gene expression of the high and low emitting lines. We used AmUBC2 as positive control. Results are expressed as where the CT threshold was achieved.

bp comparing to the $A$. majus promoter, immediately after the -852 bp of $A$. majus promoter. This insertion had homology with the VENOSA genomic locus (Schwinn et al., 2006; BLASTN 2e19). Furthermore the insertion was flanked by an 8 bp imperfect tandem duplication. Finally, the closest fragment to the start of transcription was -845 to $-1 \mathrm{bp}$, homologous to $A$. majus -851 to $-1 \mathrm{bp}$. It contained 45 SNPs, five deletions of 1-4 bp and three insertions of 1-4 bp.

Altogether the promoter of A. linkianum BAMT has two large insertions, one large deletion and several SNPs and indels, indicating that the complexity of changes may be responsible for the complete loss of expression in petals.

\section{DISCUSSION}

The identification of genes involved in the synthesis of scent and VOCs is an important effort that runs in parallel in a variety of plants. In crops, scent related traits include flavor and aroma and have undergone extensive research in many important plants such as rice (Lorieux et al., 1996; Singh et al., 2007; Golestan Hashemi et al., 2015), tomato (Klee, 2010; Klee and Tieman, 2013), strawberry (Zorrilla-Fontanesi et al., 2012), or trees such as peaches (Eduardo et al., 2013). The use of natural variation has helped first to define the genetic structure of the character and second to identify candidate genes involved in scent and volatile emission. Although scents are complex combinations of VOCs, the genetic structure of this trait has turned out to be composed of single genes and both regulatory genes such as the MYB gene ODORANT1 from Petunia (Klahre et al., 2011) and a large number of enzymes have been identified using this approach. In this study we have analyzed the genetic structure of scent emission in two species of Antirrhinum, A. majus and A. linkianum, differing in the emission of four VOCs, methyl benzoate, methyl cinnamate, acetophenone, and $\beta$-ocimene (Weiss et al., 2016b). Our results show that the different VOCs displayed Mendelian segregations imputable to one or two genes.

The results of the segregation analysis coincided with the currently known biochemical models describing the catalytic reactions leading to the formation of the last step in the synthesis of methyl benzoate, $\beta$-ocimene, methyl cinnamate, and acetophenone. However, there are several aspects that may obscure the segregation analysis of scent VOCs. First, natural alleles may result in complete loss of function such as the $A$. linkianum BAMT identified in the current work. But small albeit detectable emissions of a compound such as methyl benzoate may be synthesized by a second enzyme such as A. majus SAMT, showing low affinity for benzoic acid (Effmert et al., 2005). The capacity to transform benzoic acid by SAMT seems to be enzyme specific as the tomato SAMT SISAMT has a very low affinity for benzoic acid while the JAMT enzyme involved in the synthesis of methyl jasmonate can readily produce methyl benzoate (Tieman et al., 2010). Thus, the occasional emission of methyl benzoate could be the result of a family of proteins that have major affinities for their major substrate but maybe able to process additional metabolites with similar structures.

A second aspect is that incomplete loss of function i.e., leaky or weak alleles may result in segregations difficult to interpret as setting an emission threshold may not be straight forward. Indeed there are two possible gene models for $\beta$-ocimene synthesis, one based on a single gene, that would agree with the current biochemical model based on a single gene (Dudareva et al., 2003), while the second maybe based on two genes. As the Antirrhinum genome is not sequenced we cannot conclude if the first model is the correct one and further genetic and molecular analysis is required to resolve this issue.

The emission of methyl cinnamate appears to be recessive and the dominant allele may be a loss of function. The currently proposed biochemical model of methyl cinnamate synthesis is based on enzymes related to SHABAT carboxymethyl tranferases. This indicates that the loss of function maybe the result of a dominant negative translated gene product or the result of a local transposition event causing a double stranded RNA based gene silencing in trans.

The current model of acetophenone biosynthesis is based on the bacterial degradation of ethylbenzene by anaerobic catabolism where the last step is the degradation of 1phenylethanol (Kniemeyer and Heider, 2001). This model may be conserved in higher plants where isotope labeling has shown that 1-phenylethanol is the major substrate for acetophenone 
P.hybrida_BSMT1_AAO45012 P.hybrida_BSMT2_AAO45013 N. suaveolens_BSMT_CAF31508 H. carnosa_SAM̄T_CA 05934 S.floribunda SAMT CAC33768 A.majus_SAMT AAN 40745 C.breweri SAMT AAF00108
A.thaliana_JAMT AT1G19640 A. majus BAM̄T Q9 FYZ9 A.linkianum_BAMT_xU512978 A. thaliana SAMdependent AT5G38020 A.thaliana_BSMT_AT3G114 $\overline{80}$

P.hybrida_BSMT1_AAO45012 P.hybrida_BSMT2 AAO45013 N. suaveolens_BSMT_CAF31508 H. carnosa_SAMT CAI05934 S. A.majus_SAMT_AAN 40745 A.thaliana JAMT AT1G19640 A. majus_BAMT_Q9FYZ9

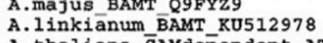
A. thaliana $\bar{S}$ AMdependent A A.thaliana_BSMT_AT3G11480

P.hybrida_BSMT1_AAO45012 P.hybrida-BSMT2 AAO45013 N. suaveolens BSMT CAF31508 H. carnosa_SAMT CAI05934 A. majus SAMT AAN40745 C.breweri_SAMT AAF00108 A.thaliana JAMT _AT1G19640 A.majus_BAMT Q9FYZ 9 A.linkianum BAMT KU512978 A.thaliana_SAMdependent A

P.hybrida_BSMT1_AAO45012 P.hybrida_BSMT2 AAO4 5013 N. suaveolēens BSMT CAF31508 H. carnosa_SAMT CAI05934
S.floribunda_SAMMTCAC33768 A.majus_SAMT AAN4 0745 A.thaliana JAMT AT1G19640 A. thallana JAMT AT1G19640 A.majus_BAMT_Q9FYz

0512978

A.thaliana SAMdependent A

P.hybrida_BSMT1_AAO45012 P.hybrida_BSMT2_AAO45013 N. suaveolens BSMT CAF 31508 H. carnosa SAMT CAI 05934 S. floribunda_SAMT CAC A.majus_SAMT AAN40745 A. thaliana JAMT AT1G19640 A.majus BAMTT $Q 9 \bar{F} Y Z 9$ A.linkianum BAMT KU512978 A.thaliana SAMdependent AT5G38020 A.thaliana_BSMT AT3G11480

P.hybrida BSMT1 AAO45012 P.hybrida-BSMT2 AAO45013 N. suaveolens_BSMT_CAF31508 H. Carnosa_SAMT CA $\bar{I} 05934$ S.floribunda_SAMT_CAC33768 A.majus_SAMT AAN 40745 C.brewer $\bar{i} i$ SAMT AAF 00108 A. thaliana JAMT̃ AT1G19640 A.majus_BAM̄T_Q9 FYZ9

A.1inkianum_BAMT_KU512978

A. thaliana SAMdependent
A. thaliana BSMT AT3G114 $\overline{8} 0$

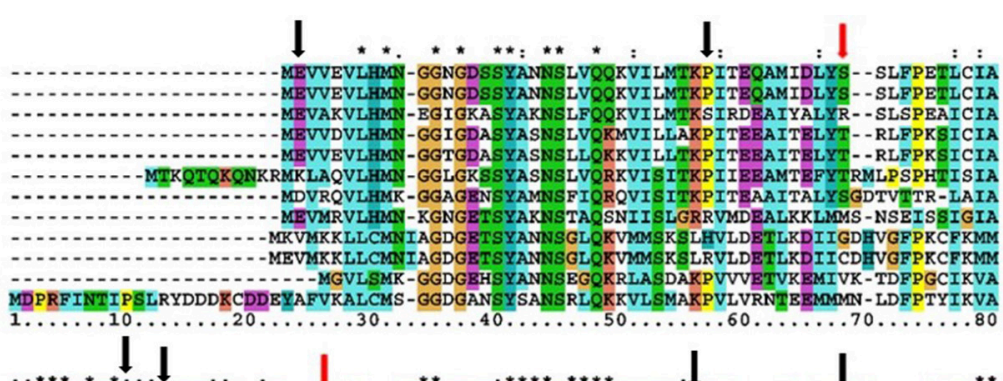

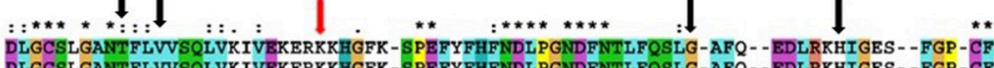
DLGCSLGANTFLVVSQLVKIVEKERKKHGFK - SPEFYFHFNDL PGNDFNTLFQSLG-AFQ- EDLRKHIGES - - FGP -CF DLGCSS GPNTFLTISELIKTIYEESXINGQKQSPEFQVFLNDL PGNDFNTI FRSLP-ALY - -EDLRKHMGDG - FGTNC DMGCSSGPNTFLAVSELIKNVEKKRTSLGHE-SPEYQIHLNDLPSNDFNTI FRSLP-SFQ--KSFSKQMGSG - - FGH-CF DLGCSCGPNTLLVAAELVKIIVKLRQKLDREPPPEFQIHLNDLPGNDFNSIFRYLLPMPR - -EBLREEIGGGEEAGRRCF

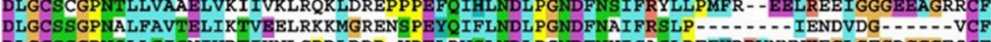

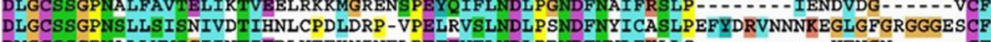
DMGCSSGPNALLVMS GI INTI IDL YTEKNINELPEFEVFLNDI PDNDFNNI FRLLS- FYDRVNNKEGLGFGRGGGESCP

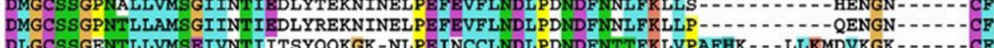
DMGCSSGPNTLLAMSGI INTIEDLYREKN INELPE FEVFLNDL PDND FNNL FKLLP ELGCSSGQNSFLAIFEI INTINVLCHVNK -NSPEIDCCLNDLPENDFNTTFKFVPFFNK

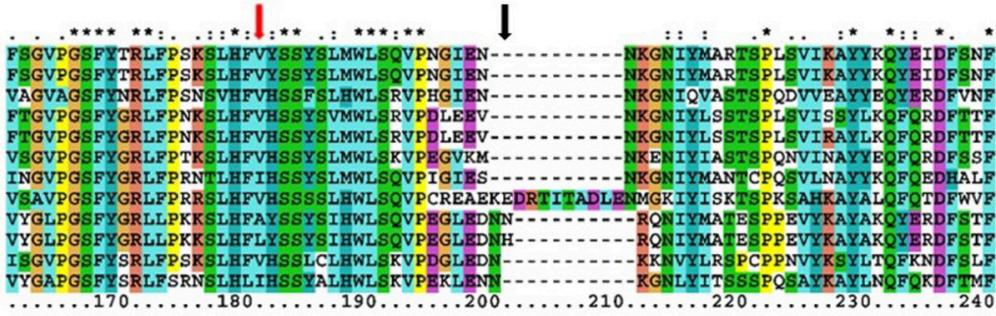

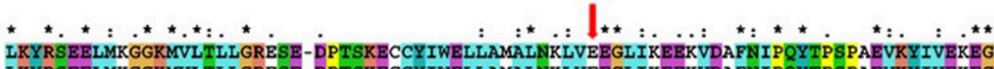
LKYRSBELMKGGKMVLTLLGRESE-DPTSKBCCY IWELLAMALNKLVEBGLIKEBKVDAFNIPQYTP P PABVKYIVBKB LKLRS I ELVKGGRMVLTVMGRNNE-DRF FKA SCY I LEPMVMAL NELIAEGSIEEEKVAAFN I PVYYP SPAEVKY IVEKE LQCRAEELVPGGVMVLTFLGRRSE-DHSGKESGYVWELLARALNBLVSEGQIEGBQLDCFNIPQYTP PAEVKYFVBEEG LQCRAEELVPGGVMVTLMGRKGE-DHSGKESGYALELLARALNELVSEGQIEEEQLDCFNVP YYTP PAEVKYFVEEEG LICRS LRCRAQEVVPGGRMVLTILGRRSE-DRASTECCLIWQLLAMALNQMVSEGLIEESKMDKFNIPQYTP SPTEVEAEILKB LRLRGE CKLRE LKLRGEEIVNGMA LRLRSEETVSNGRIVLLICRTLNDPYRDCCH LRLRSEEIVSNGRMVLTFIGRNTLNDPLYRDCCHFWTLLSNSLRDLVFEGLVSESKLDAFNMPFYDPNVQELKEVIQKEG

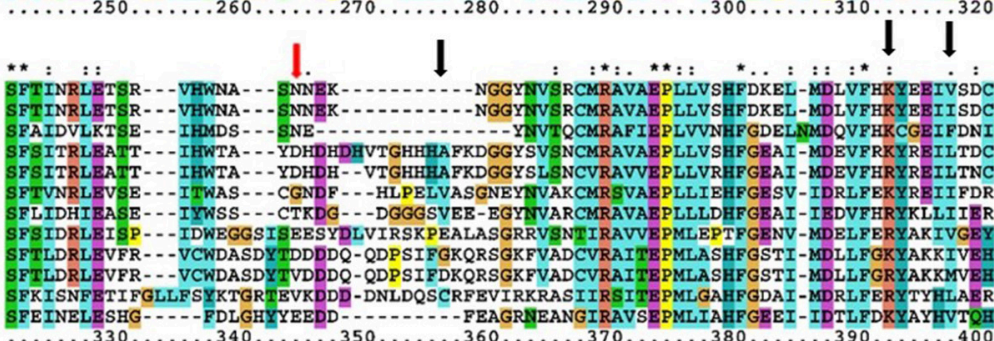

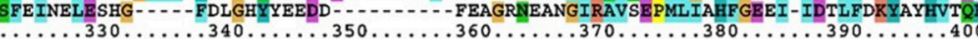

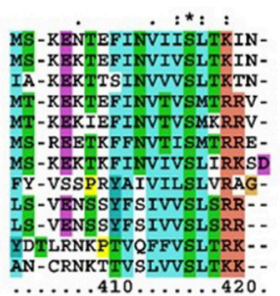

FIGURE 5 | Multiple sequence alignment of different SABATH family proteins. Petunia hybrida_BSMT1 (AAO45012), P. hybrida_BSMT2 (AAO45013), Nicotiana suaveolens_BSMT (CAF31508), Hoya carnosa_SAMT (CAI05934), Stephanotis floribunda_SAMT (CAC33768), Antirrhinum majus_SAMT (AAN40745), Clarkia breweri_BAMT (AAF00108), Arabidopsis thaliana_JAMT (AT1G19640), A. majus_BAMT (Q9FYZ9), A. linkianum_BAMT (KU512978), A.

thaliana_SAMdependent (AT5G38020), A. thaliana_BSMT (AT3G11480). Non-conserved amino acids with A. linkianum marked with red arrows, conserved amino acids with black arrows. Alignment performed with CLUSTALX (Larkin et al., 2007). Colors are default CLUSTALX color codings (Procter et al., 2010), corresponding to: blue hydrophobic; red positively charged, purple negatively charged, yellow small $(\mathrm{P})$, cyan $(\mathrm{Y}$ and $\mathrm{H})$, green polar, and orange (G). *Are conserved positions and: indicate amino acid conservative changes $>0.5$ in the Gonnet PAM 250 matrix, and a . indicates weak conservation <0.5 in the Gonnet PAM 250 matrix. 
TABLE 3 | Aminoacid polymorphisms between A. linkianum and A. majus BAMT proteins and their position.

\begin{tabular}{|c|c|c|c|c|c|c|c|c|c|c|c|c|c|c|c|}
\hline \multirow[b]{2}{*}{ A. majus } & \multicolumn{15}{|c|}{ Aminoacid } \\
\hline & $\mathrm{K}$ & $\mathrm{H}$ & $\mathbf{G}$ & A & V & $\mathbf{T}$ & S & $\mathrm{H}$ & A & $\mathrm{N}$ & A & D & G & K & 1 \\
\hline A. linkianum & $E$ & $\mathrm{R}$ & C & $\mathrm{T}$ & $A$ & $\mathbf{R}$ & $\mathrm{P}$ & $Q$ & $\mathbf{L}$ & $\mathrm{H}$ & D & $\mathbf{v}$ & $\mathrm{D}$ & $\mathrm{R}$ & $M$ \\
\hline aa-Position & 2 & 36 & 47 & 69 & 72 & 85 & 115 & 116 & 143 & 163 & 239 & 292 & 303 & 338 & 343 \\
\hline
\end{tabular}

Methionine was in the position 1 in the coding sequence of both proteins. Polymorphisms in bold are non-conserved in BAMT/SAMT proteins.
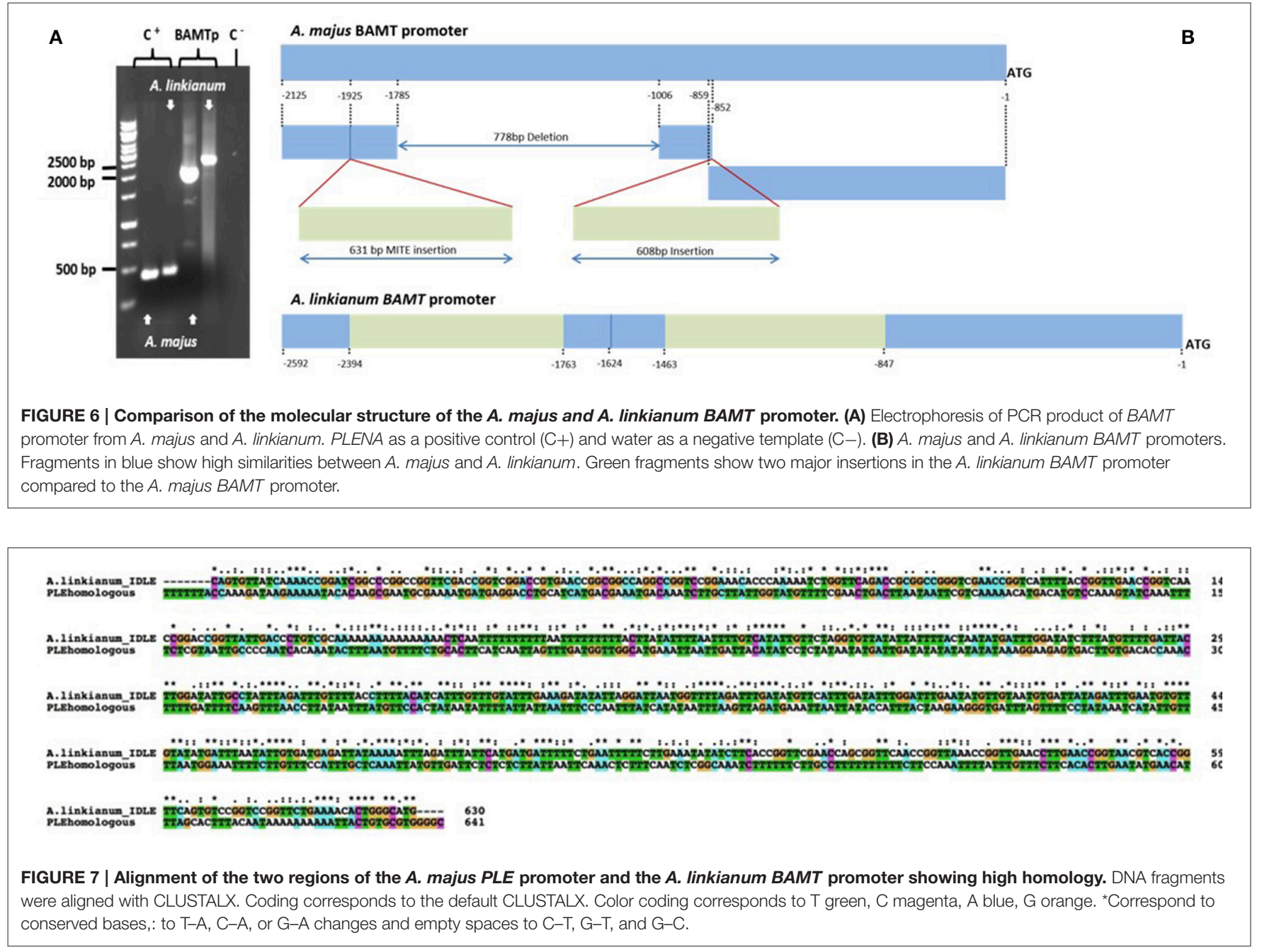

synthesis in Camellia sinensis (Dong et al., 2012). This suggests a conservation of the biochemical pathway in higher plants that probably perform this reaction under aerobic conditions. The segregation of acetophenone in the cross of $A$. majus $\times A$. linkianum was most likely due to a two gene model, supporting the current evidence in bacteria where two enzymes are required to perform the synthesis of this volatile.

The lack of BAMT mRNA in plants that did not emit methyl benzoate led us to use the $A$. majus BAMT sequence to obtain information of the A. linkianum BAMT locus. The total of fifteen amino acid changes between $A$. majus and A. linkianum BAMT coding sequences is on one hand high, but is also restricted to either conservative changes or changes in non-conserved amino acids within a set of SABATH proteins. The intron-exon boundaries and predicted splicing sites of $A$. majus and A. linkianum BAMT were conserved. This indicates that the lack of mRNA of A. linkianum $B A M T$ was not caused by alternative splicing differing between both alleles. The A. majusBAMT gene expression is circadian regulated (Kolosova et al., 2001a). We had sampled the flowers for mRNA at the highest level of recorded expression, i.e., roughly at T6 of subjective time. As we neither found $A$. linkianum BAMT expression at this point, nor methyl benzoate emission in a $24 \mathrm{~h}$ interval, our assumption is that $A$. 
linkianumBAMT does not produce mRNA at other times of the day.

However, as the mRNA was undetectable in A. linkianum or the corresponding siblings we pursued further to analyze the regulatory region of $A$. linkianum BAMT. The mutations found in the promoter of the A. linkianum BAMT gene comprise three major changes including what appears to be an event of nonhomologous recombination causing an insertion of a $630 \mathrm{bp}$ fragment that is with high probability originated at the PLENA locus. The insertion contains an IDLE transposable element that is also present in the PLENA locus (Cartolano et al., 2007). The second modification is caused by a 608 bp insertion with low homology to the VENOSA locus (Schwinn et al., 2006), flanked by two 8 bp imperfect repeats. These type of mutations maybe caused in an original promoter by a patch-mediated doublestrand break induction and repair mechanism (Vaughn and Bennetzen, 2014). We cannot determine if the 778 bp deletion occurred linked to the aforementioned events or happened independently. However, small changes such as $4 \mathrm{bp}$ deletions can give raise to weak hypomorphic alleles such as deficiens chlorantha (Schwarz-Sommer et al., 1992). So our assumption is that the complex rearrangement of the A. linkianum regulatory region creates what appears to be a null allele in terms of mRNA expression. The low emission of methyl benzoate by some of the F2 recessive lines can be explained by the non-specific production of this compound by SAMT (Effmert et al., 2005). Methyl salicylate synthesis is activated in response to stress. The gene encoding for SAMT is induced by salicylic acid and jasmonic acid in Antirrhinum petals (Negre et al., 2002). Although the reported $\mathrm{Km}$ of SAMT is over 100-fold lower for benzoic acid than salicylic acid it may be responsible for the small amounts of methyl benzoate emission that we could detect in some samples. We have not tested the hypothesis of a direct involvement of A. majus

\section{REFERENCES}

Alonso-Blanco, C., Aarts, M. G., Bentsink, L., Keurentjes, J. J., Reymond, M., Vreugdenhil, D., et al. (2009). What has natural variation taught us about plant development, physiology, and adaptation? Plant Cell 21, 1877-1896. doi: $10.1105 /$ tpc.109.068114

Bey, M., Stuber, K., Fellenberg, K., Schwarz-Sommer, Z., Sommer, H., Saedler, H., et al. (2004). Characterization of Antirrhinum petal development and identification of target genes of the class B MADS box gene DEFICIENS. Plant Cell 16, 3197-3215. doi: 10.1105/tpc.104.026724

Bradley, D., Carpenter, R., Sommer, H., Hartley, N., and Coen, E. (1993). Complementary floral homeotic phenotypes result from opposite orientations of a transposon at the plena locus of Antirrhinum. Cell 72, 85-95. doi: 10.1016/0092-8674(93)90052-R

Byers, K. J., Bradshaw, H. D. Jr, Riffell, J. A., Alarcón, R., Waser, N. M., Ollerton, J., et al. (2014a). Three floral volatiles contribute to differential pollinator attraction in monkeyflowers (Mimulus). J. Exp. Biol. 217, 614-623. doi: $10.1242 /$ jeb.092213

Byers, K. J., Vela, J. P., Peng, F., Riffell, J. A., and Bradshaw, H. D. Jr. (2014b). Floral volatile alleles can contribute to pollinator-mediated reproductive isolation in monkeyflowers (Mimulus). Plant J. 80, 1031-1042. doi: 10.1111/tpj.12702

Cartolano, M., Castillo, R., Efremova, N., Kuckenberg, M., Zethof, J., Gerats, T., et al. (2007). A conserved microRNA module exerts homeotic control over Petunia hybrida and Antirrhinum majus floral organ identity. Nat. Genet. 39, 901-905. doi: 10.1038/ng2056
$B A M T$ on the synthesis of methyl salicylate or methyl jasmonate, as we have not performed experiments under stress conditions aimed to activate these pathways. Nevertheless, methyl salicylate is amongst the most common floral scent VOCs (Knudsen et al., 2006), Our data shows that complex scent profiles can be resolved to combinations of Mendelian genes involved in synthesis or control of scent components. The high transposon activity of the Antirrhinum genus may be involved in the diversity of profiles and may play a role in local adaptation to pollinators.

\section{AUTHOR CONTRIBUTIONS}

VR-H, BH, JW, and ME-C designed experiments; performed experiments; analyzed the data; corrected and approved the final manuscript. VR-H, JW, and ME-C wrote the manuscript.

\section{FUNDING}

This work was supported by the Ministerio de Ciencia e Innovación-Fondo de Desarrollo Regional (BFU2013-45148-R) to ME-C and JW; and by the Ministerio de Educación Cultura y Deporte (FPU13/03606) to VR-H.

\section{ACKNOWLEDGMENTS}

We would like to acknowledge María José Roca for technical assistance.

\section{SUPPLEMENTARY MATERIAL}

The Supplementary Material for this article can be found online at: http://journal.frontiersin.org/article/10.3389/fpls.2017. 00027/full\#supplementary-material

Collu, G., Unver, N., Peltenburg-Looman, A. M., van der Heijden, R., Verpoorte, R., and Memelink, J. (2001). Geraniol 10-hydroxylase, a cytochrome P450 enzyme involved in terpenoid indole alkaloid biosynthesis. FEBS Lett. 508, 215-220. doi: 10.1016/S0014-5793(01)03 045-9

Colquhoun, T. A., Schwieterman, M. L., Wedde, A. E., Schimmel, B. C., Marciniak, D. M., Verdonk, J. C., et al. (2011). EOBII controls flower opening by functioning as a general transcriptomic switch. Plant Physiol. 156, 974-984. doi: 10.1104/pp.111.176248

Delgado-Benarroch, L., Causier, B., Weiss, J., and Egea-Cortines, M. (2009). FORMOSA controls cell division and expansion during floral development in Antirrhinum majus. Planta 229, 1219-1229. doi: 10.1007/s00425-009-0 910-X

Dong, F., Yang, Z., Baldermann, S., Kajitani, Y., Ota, S., Kasuga, H., et al. (2012). Characterization of l-phenylalanine metabolism to acetophenone and 1-phenylethanol in the flowers of Camellia sinensis using stable isotope labeling. J. Plant Physiol. 169, 217-225. doi: 10.1016/j.jplph.2011.1 2.003

Dudareva, N., Andersson, S., Orlova, I., Gatto, N., Reichelt, M., Rhodes, D., et al. (2005). The nonmevalonate pathway supports both monoterpene and sesquiterpene formation in snapdragon flowers. Proc. Natl. Acad. Sci. U.S.A. 102, 933-938. doi: 10.1073/pnas.0407360102

Dudareva, N., Martin, D., Kish, C. M., Kolosova, N., Gorenstein, N., Fäldt, J., et al. (2003). (E)- $\beta$-ocimene and myrcene synthase genes of floral scent biosynthesis in snapdragon: function and expression of three terpene synthase 
genes of a new terpene synthase subfamily. Plant Cell 15, 1227-1241. doi: $10.1105 /$ tpc. 011015

Dudareva, N., Murfitt, L. M., Mann, C. J., Gorenstein, N., Kolosova, N., Kish, C. M., et al. (2000). Developmental regulation of methyl benzoate biosynthesis and emission in snapdragon flowers. Plant Cell 12, 949-961. doi: 10.1105/tpc.12.6.949

Eduardo, I., Chietera, G., Pirona, R., Bassi, D., Rossini, L., Vecchietti, A., et al. (2013). Genetic dissection of aroma volatile compounds from the essential oil of peach fruit: QTL analysis and identification of candidate genes using dense SNP maps. Tree Genet. Genomes 9, 189-204. doi: 10.1007/s11295-012-0546-Z

Effmert, U., Saschenbrecker, S., Ross, J., Negre, F., Fraser, C. M., Noel, J. P., et al. (2005). Floral benzenoid carboxyl methyltransferases: from in vitro to in planta function. Phytochemistry 66, 1211-1230. doi: 10.1016/j.phytochem.2005.0 3.031

Golestan Hashemi, F. S., Rafii, M. Y., Ismail, M. R., Mohamed, M. T., Rahim, H. A., Latif, M. A., et al. (2015). The genetic and molecular origin of natural variation for the fragrance trait in an elite Malaysian aromatic rice through quantitative trait loci mapping using SSR and gene-based markers. Gene 555, 101-107. doi: 10.1016/j.gene.2014.10.048

Hermann, K., Klahre, U., Moser, M., Sheehan, H., Mandel, T., and Kuhlemeier, C. (2013). Tight genetic linkage of prezygotic barrier loci creates a multifunctional speciation island in Petunia. Curr. Biol. 23, 873-877. doi: 10.1016/j.cub.2013.03.069

Huang, H.-Y., Chien, C.-H., Jen, K.-H., and Huang, H.-D. (2006). RegRNA: an integrated web server for identifying regulatory RNA motifs and elements. Nucleic Acids Res. 34, W429-W434. doi: 10.1093/nar/gkl333

Kapteyn, J., Qualley, A. V., Xie, Z., Fridman, E., Dudareva, N., and Gang, D. R. (2007). Evolution of cinnamate/p-coumarate carboxyl Methyltransferases and their role in the biosynthesis of methylcinnamate. Plant Cell 19, 3212-3229. doi: $10.1105 /$ tpc. 107.054155

Klahre, U., Gurba, A., Hermann, K., Saxenhofer, M., Bossolini, E., Guerin, P. M., et al. (2011). Pollinator choice in Petunia depends on two major genetic Loci for floral scent production. Curr. Biol. 21, 730-739. doi: 10.1016/j.cub.2011.0 3.059

Klee, H. J. (2010). Improving the flavor of fresh fruits: genomics, biochemistry, and biotechnology. New Phytol. 187, 44-56. doi: 10.1111/j.1469-8137.2010.03 281.x

Klee, H. J., and Tieman, D. M. (2013). Genetic challenges of flavor improvement in tomato. Trends Genet. 29, 257-262. doi: 10.1016/j.tig.2012.12.003

Kniemeyer, O., and Heider, J. (2001). (S)-1-Phenylethanol dehydrogenase of Azoarcus sp. strain EbN1, an enzyme of anaerobic ethylbenzene catabolism. Arch. Microbiol. 176, 129-135. doi: 10.1007/s002030100303

Knudsen, J. T., Eriksson, R., Gershenzon, J., Ståhl, B., and Stahl, B. (2006). Diversity and distribution of floral scent. Bot. Rev. 72, 1-120. doi: 10.1663/00068101(2006)72[1:DADOFS]2.0.CO;2

Kolosova, N., Gorenstein, N., Kish, C. M., and Dudareva, N. (2001a). Regulation of circadian methyl benzoate emission in diurnally and nocturnally emitting plants. Plant Cell 13, 2333-2348. doi: 10.1105/tpc.010162

Kolosova, N., Sherman, D., Karlson, D., and Dudareva, N. (2001b). Cellular and subcellular localization of S-adenosyl-L-methionine: benzoic acid carboxyl methyltransferase, the enzyme responsible for biosynthesis of the volatile ester methylbenzoate in snapdragon flowers. Plant Physiol. 126, 956-964. doi: 10.1104/pp.126.3.956

Larkin, M. A., Blackshields, G., Brown, N. P., Chenna, R., McGettigan, P. A., McWilliam, H., et al. (2007). Clustal W and clustal X version 2.0. Bioinformatics 23, 2947-2948. doi: 10.1093/bioinformatics/btm404

Lorieux, M., Petrov, M., Huang, N., Guiderdoni, E., and Ghesquière, A. (1996). Aroma in rice: genetic analysis of a quantitative trait. Theor. Appl. Genet. 93, 1145-1151. doi: 10.1007/BF00230138

Manchado-Rojo, M., Delgado-Benarroch, L., Roca, M. J., Weiss, J., and EgeaCortines, M. (2012). Quantitative levels of Deficiens and Globosa during late petal development show a complex transcriptional network topology of B function. Plant J. 72, 294-307. doi: 10.1111/j.1365-313X.2012.05 080.x

Martin, C., Carpenter, R., Sommer, H., Saedler, H., and Coen, E. S. (1985). Molecular analysis of instability in flower pigmentation of Antirrhinum-Majus, following isolation of the pallida locus by transposon tagging. EMBO J. 4, 1625-1630.
Murfitt, L. M., Kolosova, N., Mann, C. J., and Dudareva, N. (2000). Purification and characterization of S-adenosyl-L-methionine: benzoic acid carboxyl methyltransferase, the enzyme responsible for biosynthesis of the volatile ester methyl benzoate in flowers of Antirrhinum majus. Arch. Biochem. Biophys. 382, 145-151. doi: 10.1006/abbi.2000.2008

Negre, F., Kolosova, N., Knoll, J., Kish, C. M., and Dudareva, N. (2002). Novel S-adenosyl-L-methionine: salicylic acid carboxyl methyltransferase, an enzyme responsible for biosynthesis of methyl salicylate and methyl benzoate, is not involved in floral scent production in snapdragon flowers. Arch. Biochem. Biophys. 406, 261-270. doi: 10.1016/S0003-9861(02)00 458-7

Procter, J. B., Thompson, J., Letunic, I., Creevey, C., Jossinet, F., and Barton, G. J. (2010). Visualization of multiple alignments, phylogenies and gene family evolution. Nat. Methods 7, S16-S25. doi: 10.1038/nmeth.1434

Rambla, J. L., Tikunov, Y. M., Monforte, A. J., Bovy, A. G., and Granell, A. (2014). The expanded tomato fruit volatile landscape. J. Exp. Bot. 65, 4613-4623. doi: $10.1093 /$ jxb/eru128

Sánchez, G., Venegas-Calerón, M., Salas, J. J., Monforte, A., Badenes, M. L., Granell, A., et al. (2013). An integrative "omics" approach identifies new candidate genes to impact aroma volatiles in peach fruit. BMC Genomics 14:343. doi: 10.1186/1471-2164-14-343

Schiestl, F. P. (2010). The evolution of floral scent and insect chemical communication. Ecol. Lett. 13, 643-656. doi: 10.1111/j.1461-0248.2010.0 1451.x

Schwarz-Sommer, Z., Gübitz, T., Weiss, J., Gómez-di-Marco, P., DelgadoBenarroch, L., Hudson, A., et al. (2010). A molecular recombination map of Antirrhinum majus. BMC Plant Biol. 10:275. doi: 10.1186/1471-2229-10-275

Schwarz-Sommer, Z., Hue, I., Huijser, P., Flor, P. J., Hansen, R., Tetens, F., et al. (1992). Characterization of the Antirrhinum floral homeotic MADS-box gene deficiens: evidence for DNA binding and autoregulation of its persistent expression throughout flower development. EMBO J. 11, 251-263.

Schwinn, K., Venail, J., Shang, Y., Mackay, S., Alm, V., Butelli, E., et al. (2006). A small family of MYB-regulatory genes controls floral pigmentation intensity and patterning in the genus Antirrhinum. Plant Cell 18, 831-851. doi: $10.1105 /$ tpc. 105.039255

Simon, M. J., Osslund, T. D., Saunders, R., Ensley, B. D., Suggs, S., Harcourt, A., et al. (1993). Sequences of genes encoding naphthalene dioxygenase in Pseudomonas putida strains G7 and NCIB 9816-4. Gene 127, 31-37. doi: 10.1016/0378-1119(93)90613-8

Singh, R., Singh, A. K., Sharma, T. R., Singh, A., and Singh, N. K. (2007). Fine mapping of aroma QTLs in basmati rice (Oryza sativa $\mathrm{L}$ ) on chromosomes 3, 4 and 8. J. Plant Biochem. Biotechnol. 16, 75-82. doi: 10.1007/BF033 21978

Spiller, M., Berger, R. G., and Debener, T. (2010). Genetic dissection of scent metabolic profiles in diploid rose populations. Theor. Appl. Genet. 120, 1461-1471. doi: 10.1007/s00122-010-1268-y

Tieman, D., Zeigler, M., Schmelz, E., Taylor, M. G., Rushing, S., Jones, J. B., et al. (2010). Functional analysis of a tomato salicylic acid methyl transferase and its role in synthesis of the flavor volatile methyl salicylate. Plant J. 62, 113-123. doi: 10.1111/j.1365-313X.2010.04128.x

Van Moerkercke, A., Haring, M. A., and Schuurink, R. C. (2011). The transcription factor EMISSION OF BENZENOIDS II activates the MYB ODORANT1 promoter at a MYB binding site specific for fragrant petunias. Plant J. 67, 917-928. doi: 10.1111/j.1365-313X.2011.04644.x

Vargas, P., Carrió, E., Guzmán, B., Amat, E., and Güemes, J. (2009). A geographical pattern of Antirrhinum (Scrophulariaceae) speciation since the Pliocene based on plastid and nuclear DNA polymorphisms. J. Biogeogr. 36, 1297-1312. doi: 10.1111/j.1365-2699.2008.02059.x

Vaughn, J. N., and Bennetzen, J. L. (2014). Natural insertions in rice commonly form tandem duplications indicative of patch-mediated doublestrand break induction and repair. Proc. Natl. Acad. Sci. U.S.A. 111, 6684-6689. doi: 10.1073/pnas.1321854111

Weiss, J., Alcantud-Rodriguez, R., Toksöz, T., and Egea-Cortines, M. (2016a). Meristem maintenance, auxin, jasmonic and abscisic acid pathways as a mechanism for phenotypic plasticity in Antirrhinum majus. Sci. Rep. 6, 2-11. doi: 10.1038/srep19807

Weiss, J., Mühlemann, J. K., Ruiz-Hernández, V., Dudareva, N., and EgeaCortines, M. (2016b). Phenotypic space and variation of floral scent profiles 
during late flower development in Antirrhinum. Front. Plant Sci. 7:1903. doi: $10.3389 /$ fpls.2016.01903

Zorrilla-Fontanesi, Y., Rambla, J.-L., Cabeza, A., Medina, J. J., SánchezSevilla, J. F., Valpuesta, V., et al. (2012). Genetic analysis of strawberry fruit aroma and identification of O-methyltransferase FaOMT as the locus controlling natural variation in mesifurane content. Plant Physiol. 159, 851-870. doi: 10.1104/pp.111.188318

Zu, P., Blanckenhorn, W. U., and Schiestl, F. P. (2016). Heritability of floral volatiles and pleiotropic responses to artificial selection in Brassica rapa. New Phytol. 209, 1208-1219. doi: 10.1111/nph.1 3652
Conflict of Interest Statement: The authors declare that the research was conducted in the absence of any commercial or financial relationships that could be construed as a potential conflict of interest.

Copyright $\odot 2017$ Ruiz-Hernández, Hermans, Weiss and Egea-Cortines. This is an open-access article distributed under the terms of the Creative Commons Attribution License (CC BY). The use, distribution or reproduction in other forums is permitted, provided the original author(s) or licensor are credited and that the original publication in this journal is cited, in accordance with accepted academic practice. No use, distribution or reproduction is permitted which does not comply with these terms. 